\title{
The Lamination and Arterial Blood Supply of the Masseter Muscle in the Donkey
}

\author{
Y.R.Wally and F.M.Farag \\ Department of Anatomy, Faculty of Veterianry Medicine, Cairo University
}

received February 2008, accepted for publication April 2008

\section{Introduction}

The masseter muscle attracted the attention of many investigators as it is considered the most important muscle of mastication. The lamination of the masseter muscle has been described by Toldot (1905) in the human and domestic animals, Yoshikawa et al. $(1961,1962)$ in mammals and ruminants respectively, Yoshikawa and Suzuki (1965) in mammals and Sasaki et al. (2001) in the giraffe.

The arterial supply to the masseter muscle was described by Fujiwara (1970) in the goat and dog, Kenawy (1973) in the camel, El-Ayat (1977) in the buffalo, Suzuki $(1980,1982,1984)$ in the monkey, horse and cow respectively and Daghash (2007) in the goat. Mathes and Nahai (1981) in man and Chambers et al. (1990) in the dog, ranked the arterial vascular pedicles supplying muscles into dominant, major and minor by relative amount of muscle each supplied. Mathes and Nahai (1981) divided five categories according to the vascular pattern system of muscles as follows:. Type I: one vascular pedicle. Type II: dominant vascular pedicles plus minor vascular pedicles entering the muscle .Type III: two dominant pedicles. Type IV: segmental vascular pedicles (multiple pedicles entering one muscle) Type $\mathrm{V}$ : one dominant pedicle and multiple secondary pedicles.

Little is known about the structure of the masseter muscle and its arterial supply in the donkey, so the present study is carried out to investigate the structure of the masseter muscle and its attachments to the skull as well as the relationships with its arterial blood supply, aiming to give a detailed information, increasing anatomical knowledge for that animal which may be of help in clinical work.

\section{Materials and Methods}

Twelve heads of clinically healthy donkeys of different ages and sexes were used in the present investigation. Catheters of size 12\&14 were fixed in both right and left common carotid arteries. Heads were thoroughly flushed with warm (40c) saline solution. Specimens were injected with formalin solution ( $10 \%$ formalin, $4 \%$ phenol, $1 \%$ glyc- erin), followed by immersion in formalin solution for 3-4 days (Tomsett and Wakelly, 1965).

Four heads were used in manual dissection to describe the laminar arrangement of the masseter muscle.

Six specimens were injected with gum milk latex $(60 \%)$ colored red with Rotring ink. Each needed approximately $200-250 \mathrm{ml}$ of latex, then preserved in a cold room for 3-4 days before dissection (Hildebrand, 1968).

Two heads were injected with an eventually mixture of $75 \mathrm{gm}$ red lead oxide in $150 \mathrm{cc}$ latex and preserved in a cold room for 3-4 days then divided sagittaly along the median plane to avoid super imposition of the arteries. The arteries of the masseter muscle of each half were radiographed using $52 \mathrm{KVP}, 48 \mathrm{~mA}, 0.5$ second and FFD $70 \mathrm{~cm}$ (Ozek et al. 1996).

Nomenclature was adopted according to Nomina Anatomica Veterinaria (2005).

\section{Results}

\section{A- Lamination of the masseter muscle:}

In the donkey the masseter muscle was recognized into proper and improper masseter groups. The proper group included the first, second superficial, intermediate and deep masseter layers. The improper group consisted of maxillo-mandibularis and zygomatico-mandibularis.

The first superficial layer (figs.1, 2, 3, 6/1, 9/1) of the masseter muscle appeared quadrilateral in shape. It originated from the lateral border of the facial crest and zygomatic process of the zygomatic bone by a thick strong glistening tendinous sheet. The tendon fibers proceeded in a slightly caudoventral direction and became thin and the muscular fibers began to appear between them at the distal fourth of this layer. It terminated with fleshy substance at the lateral margin of the ven- 
tral and caudal border of the Ramus of the mandibulae behind the vascular notch (fig10/2).

The rostral border the tendon of the $1^{\text {st }}$ superficial layer turned around forming a compact tendon (fig.2, /2, 9/1', 1") and continued medially for about $4 \mathrm{~cm}$. enclosed a thick muscular portion(second superficial, intermediate and first layer of maxillomandibularis) related medially to the molar part of the buccinator muscle. It continued ventrally by a muscular portion and terminated at the ventral border of the Ramus of the mandible.

A small muscular portion (fig.1/2, 2/3) appeared dorsal and medial to the caudo-dorsal border of the first superficial layer represented the caudal part of the deep masseter.

After cutting the muscular substance of the first superficial layer along its insertion and removal of the muscle fibers, the underlying tendinous sheet of the second superficial layer appeared. Reverse relationship between the tendinous and muscular constituent of the succeeding layers of the proper masseter muscle was observed.

The second superficial layer (fig.4/1,6/2,9/2) took its origin from the ventral border of the facial crest and the zygomatic process of the zygomatic bone medial to the $1^{\text {st }}$ superficial layer by a thin fleshy part. Its fibers were directed caudo-ventrally to be inserted by a thin tendentious sheet medial to the insertion of the $1^{\text {st }}$ superficial layer.

By scraping off the $2^{\text {nd }}$ superficial layer along its muscular part, the underlying tendon of the intermediate masseter muscle (fig.5/1, 6, 9/3) appeared. It originated from the ventro-medial aspect of the facial crest by a thin tendinous part which continued caudo-ventrally by a thin fleshy part which terminated medial and dorsal to the preceding layer at an oblique rough line (fig.10 13)about $1-1.5 \mathrm{~cm}$ dorsal to the ventral border of the mandibular Ramus.

The deep layer of the masseter muscle (fig.7/ 1, 1') appeared after scraping of the preceding layer at its muscular insertion. It originated from the ventromedial aspect of the caudal two thirds of the facial crest and the zygomatic processes of the maxillary and temporal bones. It was divided into an rostral and caudal portions by the masseteric nerve. The fibers of the rostral portion extended from the ventro-medial aspect of the facial crest deep to the intermediate layer and proceeded in a nearly vertical direction. The caudal portion appeared thicker and consisted of several layers that alternated their tendons and muscular substance. Both rostral part and caudal part of the deep masseter muscle occupied the deep masseteric fossa and termi-

J. vet. anat. nated into an oblique rough line at the lateral surface of the ramus of the mandible (fig.10/4).

The improper masseter muscle (fig.12) could be distinguished into maxillomandibularis and zygomaticomandibularis muscles. The maxillomandibularis arranged into two layers first and second. The first layer originated by a thin muscular part from the rostral half of the facial crest $(5 \mathrm{~cm})$ and descended to be terminated by a thin tendon at the rostro- ventral part of the ventral border of the Ramus of the mandible(fig. $7 / 2,9 / 5$ ). The second layer appeared after scraping of the first layer (fig. 8/1). It began by a thick tendinous part and proceeded vertically to be inserted deep to the preceding layer.

The M. zygomatico-mandibularis (fig8/2, 9/6) was represented by a short thick muscle which originated from the rostral part of the ventral border of the zygomatic process of the temporal bone, in front of tempromandibular joint and zygomatic process of the maxillary bone. It descended in a cranio-ventral direction to be inserted in an oblique rough line about $1.5 \mathrm{~cm}$ distal to the rostral border of the Ramus of the mandible (fig. 10/5).

\section{B- Arterial supply:}

\section{A. massetericus}

The masseteric artery (fig.1, 3, 4, 5, 6, 13,14/B) originated from the lateral aspect of the external carotid artery. It proceeded rostroventral to the caudoventral portion of the first superficial layer of the masseter muscle and pierced it to the subjacent layers. It continued rostrally and terminated by dividing into two branches that were distributed to the deep masseteric layer and maxillomandibular layer.

Along its course, it released one to three fine branches (fig. 3 /B') which supplied the caudoventral portion of the first superficial layer. Two or three branches (fig. 4,5/B') detached from its dorsal aspect proceeded rostro-dorsally and supplied the ventral portions of the second superficial, intermediate, ventral portions of the deep masseteric layers as well as the maxillo-mandibular layers of the masseter muscle.

\section{A. transversa faciei:}

The transverse facial artery (fig .3, 4, 5, 13, 14/A) originated from the superficial temporal artery. It passed in a rostro-dorsal direction released a short R. articularis (fig 13,14/RA) from its dorsal aspect to the tempromandibular joint and a superficial branch (fig.3, 4/A, 14/A1) on the lateral surface of the masseter muscle. Then it dipped between the deep masseteric layer and zygomatico-mandibular 
muscle as a deep branch (fig. 9, 10/A2) which continued rostrally about $1-5 \mathrm{~cm}$ before dividing into a dorsal and a ventral branch deep to the caudal part of the deep masseter muscle.

The superficial branch (fig. 4/A, 14/A1) passed rostrally on the first superficial layer of the masseter muscle, detached two dorsal and two-three ventral branches to its caudo-dorsal portion and dipped into the dorsal parts of the second superficial, intermediate and deep masseteric layers. It terminated by anastomosing with the masseteric branches of the facial artery.

The R. dorsalis (fig.13, 14 /A3) of the deep branch of the transverse facial artery passed rostrodorsal and distributed to the dorsal parts of the caudal deep and zygomatico-mandibular masseteric layers.

The R. ventrails (fig.13,14/A4) of the deep branch of the transverse facial artery proceeded rostroventrally along the ventral border of the M. zygomatico-mandibularis. It run deep to the caudal part of the deep masseter muscle, releasing several fine branches to it and to the caudal deep masseteric layer. It terminated at the medial surface of the maxillo-mandibular part of the improper masseter muscle.

\section{A. buccalis:}

The buccal artery (fig.14/D) originated from the $3^{\text {rd }}$ part of the maxillary artery. It turned around the maxillary tuber and proceeded rostro-ventral, deep to the improper masseter muscle releasing several fine branches which supplied the medial surface of the maxillo-mandibular layer of the masseter muscle.

\section{A. facialis:}

The facial artery (fig.3, 4, 5, 13/C) represented the continuation of the linguo-facial artery. It proceeded dorsally along the rostral border of the masseter muscle. The facial artery provided one ventral and two or three dorsal masseteric branches to the rostral part of the masseter muscle. The former branch (fig.3, 4, 5, 13/C') was the largest, it ascended in a caudo-dorsal direction to the rostroventral portion of the first superficial masseteric layer and dipped into the second superficial, intermediate and rostral deep masseteric layers. The other dorsal branches (fig.3, 4, 5/C") leaved the rostro-dorsal portion of the first superficial masseteric layer and dipped into the rostral portions of the second superficial, intermediate, rostral deep and maxillo-mandibular masseteric layers to terminate by joining the branches of the transverse facial artery.

J. vet. anat.
The masseter muscle was classified as type II (according to the classification of Mathes and Nahai, 1981). It received two dominant arteries (masseteric and transverse facial) and minor arterial pedicles (masseteric branches of facial and buccal arteries)

\section{Discussion}

The masseter muscle was alternately partitioned by the upper and lower tendinous sheets into several layers (Schumacher, 1961; Yoshikawa et al., 1961, 1962; Sasaki et al.2000 a, b.). In this study the anatomical terms were adopted according to the description of Yoshikawa et al. $(1961,1962)$ in mammals and ruminants. The masseter muscle of the herbivorous ungulates (horse, goat, sheep, cattle, deer and camel) was divided into superficial, intermediate and deep portions, in addition to maxillo-mandibular and zygomatico-mandibular parts as an improper masses of the muscle.

In the donkey the masseter muscle was the largest of the muscles involved in mastication. Such result was reported by Smith and Savage (1959), Schumacher (1961), Turnbull (1970) and Koppe et al.(1987) in the mammals. However, the masseter muscle of the ruminant is less developed because of chewing the already half digested cud (Janis and Jarman, 1984).

The current study revealed the presence of a reverse relationship between the tendinous and muscular constituent of the succeeding layers of the proper masseter muscle. Similar observations were also recorded by Yoshikawa and Suzuki (1965) in mammals. They also added that t cutting of muscular substance of every layer must be done along its terminal line to determine the tendon of the underlying layer.

The current study revealed that the facial crest was elongated, the space between it and the ventral border of the mandible was relatively long and the presence of the deep masseteric fossa lead to a long and thick masseter muscle.Such results were in accordance to that recorded in the horse (Heinze ,1963 a,b) and Turnbull (1970). They added that the masseter muscle is divided into more layers by more tendinous sheets than that of the ruminant. In this respect, Sasaki et al (2001) mentioned that the lamination of the masseter muscle in the giraffe was not complicated as compared with the horse. The giraffe can get soft, high quality foods without competition because of its long neck and tongue (Pellew, 1984 and Nowak, 1991). They added that these may be the reasons why the giraffe had a lower masseteric function.

In the present work the first superficial layer arose by a strong tendinous sheet from the facial crest 
and the zygomatic process of the zygomatic bone and inserted by a fleshy portion on the ventral and distal part of the caudal borders of the mandible. The same results were reported in the horse by Sisson (1975). While in the cattle, sheep and deer it was originated from the facial crest with its fleshy portion, inserted into the tubercle of the mandible through the strong tendinous sheet (Sasaki et al, 2001).

In the donkey, the rostral part of the most superficial tendinous sheet turned around as a compact tendon and was attached to the medial part of the facial crest. Such observations was detected by Heinze (1963 b) in the horse, Sasaki et al (2001) in the giraffe.

In accordance with Sisson (1975) in the horse there was a small part near the tempromandibular joint not covered by the superficial layer. The current study proved that it was the caudal part of the deep masseter muscle.

In the present work the deep masseter muscle occupied the dorsal part of the masseteric fossa and divided into rostral part and caudal part by the masseteric nerve. Such result was described by Yoshikawa and Suzuki (1965) in mammals. The caudal par twas composed of several layers, their tendon alternate with the muscular substance.

The function of the masseter muscle includes chewing movement which was performed by the proper masseter group and firm closure of the mouth which is performed by the improper masseter group (Yoshikawa and Suzuki ,1965) they added that the improper muscle moves the mandible in lever style.

In accordance with Yoshikawa et al. (1961) in ungulates, and Heinze $(1963, \mathrm{~b})$ in the horse, the maxillo-mandibular muscle in the donkey was recognized into first and second layers. Heinze $(1963, b)$ in the horse, mentioned that the first superficial layer and the second layer of the maxillomandibular muscle could be considered as a single layer because their tendons undergo the secondary fusion in a u-form in cross section. These results match the results of the present study.

In the present study the zygomatico-mandibular muscle was relatively thicker than the maxillomandibular one as revealed in the horse and Indian elephant which leads to firm closure of the mouth during mastication(Yoshikawa and Suzuki, 1965).

The pattern of the blood supply to the masseter muscle determined its importance as a chief muscle of mastication.
In the present work the masseteric artery was long and stout vessel originated from the external carotid artery. It proceeded rostroventral to the first superficial layer of the masseter muscle. It was distributed to the caudoventral portions of the first, second superficial, intermediate, rostral deep and maxillo-mandibular layers of the masseter muscle. Similar findings were also recorded by Suzuki (1982, 1984) in the horse and cow respectively. Moreover, the author mentioned also that in the cow the masseteric artery supplied the pars posterior (caudal part) of the deep masseter layer. Ghoshal (1975) in domestic animals, El Ayat (1977) in the buffalo, Abd El-Moaty (1980) in the donkey and Attia (1982) in the mule, described the masseteric artery as originating from the external carotid artery and share in the blood supply of the masseter muscle. Daghash (2007) in the goat described one to three variable sized masseteric branches which originated from the external carotid artery and were distributed to the caudal part of the superficial and caudal deep layers of the masseter muscle.

The present investigation revealed that the transverse facial artery provided the main blood flow to the dorsal parts of both proper and improper group of the masseter muscle through its superficial and deep branches. Similar observations were recorded in the horse by Suzuki (1982). On the other hand, Daghash (2007) in the goat mentioned that the transverse facial artery detached dorsal, ventral and medial branches supplying the first, second superficial, intermediate and maxillomandibular layers. However, in the cow and dog the transverse facial artery was not extended to the rostral part of deep masseter muscle and zygomatico-mandibular muscle. In addition, in the goat, Ghoshal (1975) mentioned that, the transverse facial artery was well developed in place of the facial artery which is absent in this species.

The current study revealed that the masseteric branches of the facial artery were represented by three to four rami and designated according to their distribution through the muscle into ventral branch and 2-3 dorsal ones. Suzuki (1984) in the cow also observed many masseteric branches that leave the facial artery to supply the masseter muscle.

The ventral branch was the largest of the masseteric branches and it ramified through the rostroventral part of the first superficial layer and dipped into the second superficial and intermediate layers. Such results were similar to that reported by Suzuki (1984) in the cow. In the horse Suzuki (1982) observed that the masseteric branches of the facial were extended to the maxillo-mandibular layer of the masseter muscle. 
In the present investigation the buccal artery detached three to five masseteric branches distributed to the improper group of the masseter muscle. Similar finding were reported by Daghash (2007) in the goat where the buccal artery form the main blood supply to the maxillo-mandibular and zygomatico-mandibular layer of the masseter muscle. In the horse Suzuki (1982) added that the branches of the buccal artery extended to supply the intermediate and second superficial layers of the masseter muscle which is not observed in the present work. In the cow Suzuki (1984) reported that the buccal artery supplied all layers of the masseter muscle except the deep one.

It is relevant to point out that, the masseteric branch of the caudal deep temporal artery observed in the horse by Ghoshal (1975), dog by Suzuki (1977) and cow by Suzuki (1984) can not be observed in the current study, a finding that agreed that of Suzuki (1982) in the horse.

According to the classification of Mathes and $\mathrm{Na}$ hai (1981) the masseter muscle was considered as type II, as it received two dominant pedicles (masseteric and transverse facial arteries) plus minor vascular pedicles (masseteric branches of facial and buccal arteries).

\section{References}

Abd EL-Moaty, H.A. (1980):

Morphological studies on the arterial and venous blood vessels in the head region of the donkey in Egypt.

Ph.D. Thesis, Faculty of veterinary medicine, Zagazig Univeristy, Egypt.

Attia, M. (1982):

Arteries and veins of the head and neck of the mule (Equus hinnus).

Ph.D. Thesis, Faculty of veterinary medicine, Assuit University Egypt.

Daghash, S.M. (2007):

Anatomical studies on the arteries of the head in the goat with special reference to the arterial distribution inside the muscles of mastication, principle salivary glands and tongue.

Ph.D. Thesis, Faculty of veterinary medicine, Cairo Univeristy, Egypt

EL-Ayat, M.A. (1977):

Morphological studies on the arterial and venous blood vessels in the head region of the buffalo in Egypt (Bos bubalis L.).

Ph.D. Thesis, Faculty of veterinary medicine, Cairo University, Egypt.

Fujiwara, I. (1970):

Stereological studies on several ducts and vessels by injection method of acrylic re- sin. XXVII. Arterial distribution of the masseter muscle in some mammals.

Okajimas, Fol.Anat.Jap. 47: 335-352.

Chambers, J.N.; P.T. Purinton, S.W. Allen and J.L. Moore (1990): Identification and anatomic categorization of the vascular pat terns to the pelvic limb muscles of dogs. American Journal of Veterinary Research, 51 (2): 305-313.

Ghoshal, N.G. (1975):

In Sisson and Grossmans. The anatomy of the domestic animals- $5^{\text {th }}$ ed. W.B. Saunders comp., Philadelphia, London, Toronto.

Heinz, W. (1963a):

Die Morphologie der Kaumuskulatur des Pferdes . Anat. Anz. 112:101-128.

Heinz, W. (1963b):

Die Morphologie der Kaumuskulatur des Pferdes. Anat. Anz. 113:119-130.

Hildebrand, M. (1968):

Anatomical Preparations. University of California Press. Berkeley and Los Angeles, California.

Janis, C., and P. J. Jarman, (1984): the Hoofed Mammals. The Encyclopedia of Mammals. Vol, II, (D. Macdonald, ed.), Lon don. George Allen \& Unwin, pp, 468-479.

Kenawy, A. (1973):

Arteries of the head of the camel. M.V.Sc. Thesis, Faculty of veterinary medicine, Assuit University, Egypt.

Koppe, T., B. Schumacher, and K,-U, Schumacher, 1987: Funktionelle Morphologie des maxillo-mandibularen Apparates beim Miniaturschwein Mini-Lewe.Anat. Anz. 164:181-188.11-

Mathes, S.J. and F. Nahai (1981): Clinical Applica tions for Muscle and Musculocutaneous Flaps. Experimental considerations. pp. 138-149. St Louis: The Mosby Co.

Mathes, S.J. and F. Nahai (1981): Classification of the vascular anatomy of muscles: experimental and clinical correlation. Plastic and Reconstructive Surgery, 67 (2): 177-187.

Nomina Anatomica Veterinaria (2005): $5^{\text {th }}$ edition. Prepared by the international Committee on Veterinary Gross Anatomical Nomenclature (I.C.V.G.A.N) and authorized by the General Assembly of the World Association of Veterinary Anatomists (W.A.V.A.), Knoxville, TN (USA). Published by the Editorial Committee, Hannover, Columbia, Gent, Sapporo.

Nowak, R, W. (1991): Giraffe

In: Walker's mammals of the world. Vol. 2, $4^{\text {th }}$ ed. London: Hopkins University Press. pp. 1402-1405. 
Ozek, C.; F. Zhang, W.C. Lineaweaver, B.T. Chin, L. Newlin, P. Mayer and H.J. Buncke (1996):

New simplified radio-opaque injection technique for visualization of rat arteries. Microsurgery. Vol. 17: 321-323.

Pellew, R. A. (1984): Giraffe and Okapi.

In: The Encyclopedia of mammals, Vol, II, (D. Macdonald, ed.). London: George Allen \& unwin, pp. 534-541.

Sasaki, M., H. Endo, M. Yamamoto, K. Arishi ma, and Y. Hayahi, (2000a):

Adaptation of the muscles of mastication to the flat skull feature in the polar bear (Ursus maritimus).

J. Vet. Med. Sci. 62, 7-14

Sasaki, M., H. Endo, M. Yamamoto, K. Arishi ma, and Y. Hayahi, (2000b):

The superficial layer of the Musculus masseter and well developed process of the maxilla in the tiger (Panthera tigris). Mammal Study 25, 27-34.

Sasaki, M.; Endo, H.; Kogiku, H.; Kitamura, N.; Yamada, J.; Yamamoto, M,; Arishima, $K$. and Hayashi, Y. (2001):

The structure of the masseter muscle in the Giraffe (Giraffa ca melopardalis).

Anat. Histol. Embryol., Vol. 30, Pp. 313319.

Schumacher, R. J. G., (1961):

Funktionelle Morphologie der Kamuskulatur. Jena: VEB Gustav Fischer Verlag, pp. 1-202.

Sisson, S. (1975):

Equine digestive system in Getty, R.: Sisson and Grossman's The anatomy of the domestic animals. 5th edition, vol. I \& II, W. B. Saunders Company, Philadelphia. London.
Smith, J. M., and R. J. G. Savage, (1959):

The mechanics of mammalian jaws, School Sci, Rev, 40, 289-301.

Suzuki, T. (1977):

On the arterial supply of the mas seter muscle in the dog and cat. Acta Anatomica Nippon.52:299-308.

Suzuki, T. (1980):

On the arterial supply of the masseter and temporalis muscles in the crab- eating monkey. Acta Anatomica Nippon. 55: 515524.

Suzuki, T. (1982):

On the arterial supply of the mas sete muscle in the horse. Jpn. J. Vet. Sci. 44: 503510.

Suzuki, T. (1984):

Arterial supply to the masseter muscle in the cow. Jpn. J. Vet. Sci. 46 (5): 659-667.

Toldt, C. (1905):

Der Winkelfortsatz des Unterkiefers beim Menschen und bei den Saeugetieren und die Beziehung der Kaumuskulatur zu demselben. Teil. II. Sitz. K. Akad. Wiss. Wien. Math. Nat. K1. 114, 315-476.

Turnbull, W.D. (1970):

Mammalian masticatory apparatus. Fieldiana Geol. 18, 149-356.

Yoshikawa, T., Suzuki, T., Kiuchi, R. and Mat suura, $H$. (1961):The comparative anato my of the musculus masseter of the mam mals.Acta Anat. Nippon. 36:53-71.

Yoshikawa, T., Suzuki, T., Kiuchi, R. and Mat suura, H. (1962): The lamination of the masseter of the ruminantia. Acta Anat. Nippon. 37:430-442.

Yoshikawa, T., Suzuki, T. (1965):

The comparative anatomical study of the masseter of the mammal II. Okajimas Fol. Anat. Jpn. 40:339-363. 

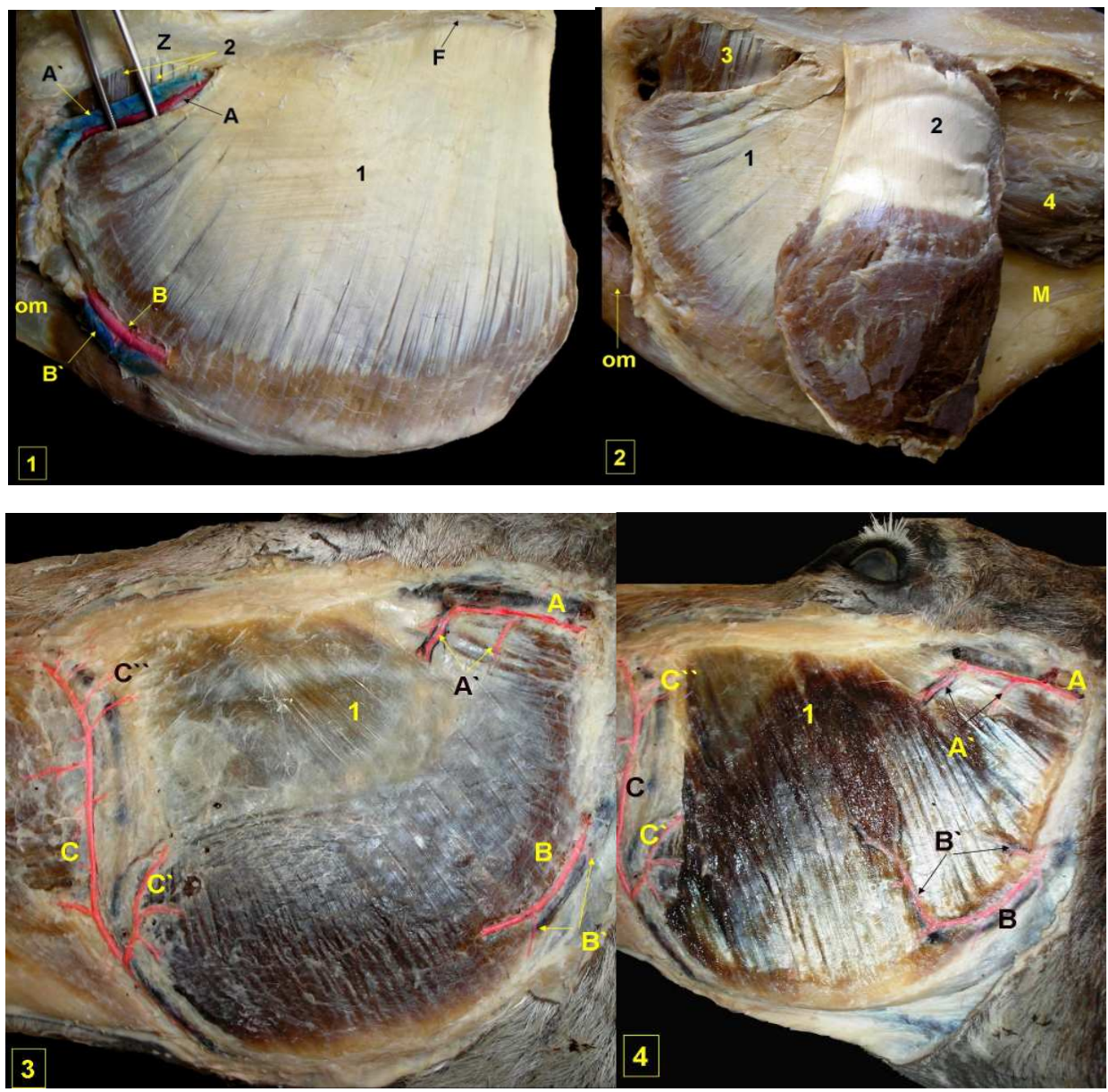

Fig. (1) A photograph showing the first superficial layer of the masseter muscle (right side).

A Transverse facial artery, A' Transverse facial vein, B Masseteric artery, B' Masseteric vein, F Facial crest, Z Zygomatic arch, Om occpito-mandibularis muscle, 1 First superficial layer of the masseter muscle, 2 Caudal part of the deep masseter muscle

Fig. (2) A photograph showing the turned tendon of the first superficial layer of the masseter muscle (right side). M Ramus of the mandible, Om occpito-mandibular muscle, 1 First superficial layer of the masseter muscle, 2 Turned tendon, 3 Caudal part of the deep masseter muscle, 4 Molar part of buccinator muscle.

Fig. (3) Photograph showing the arterial blood supply of the $1^{\text {st }}$ superficial layer of the masseter muscle (left side). A Transverse facial artery (superficial branch), A' Muscular branches of A, B Masseteric artery, B' Muscular branches of B, C Facial artery, C' Ventral muscular branch of C, C" Dorsal muscular branches of C, 1 First superficial layer of the masseter muscle.

Fig. (4) Photograph of showing the $2^{\text {nd }}$ superficial layer of the masseter muscle. (Left side).

A Transverse facial artery (superficial branch), A' Muscular branches of A, B Masseteric artery, B' Muscular branches of B, C Facial artery, C' Ventral branch of C, C" Dorsal muscular branches of C, 1 Second superficial layer of the masseter muscle.

J. vet. anat. 

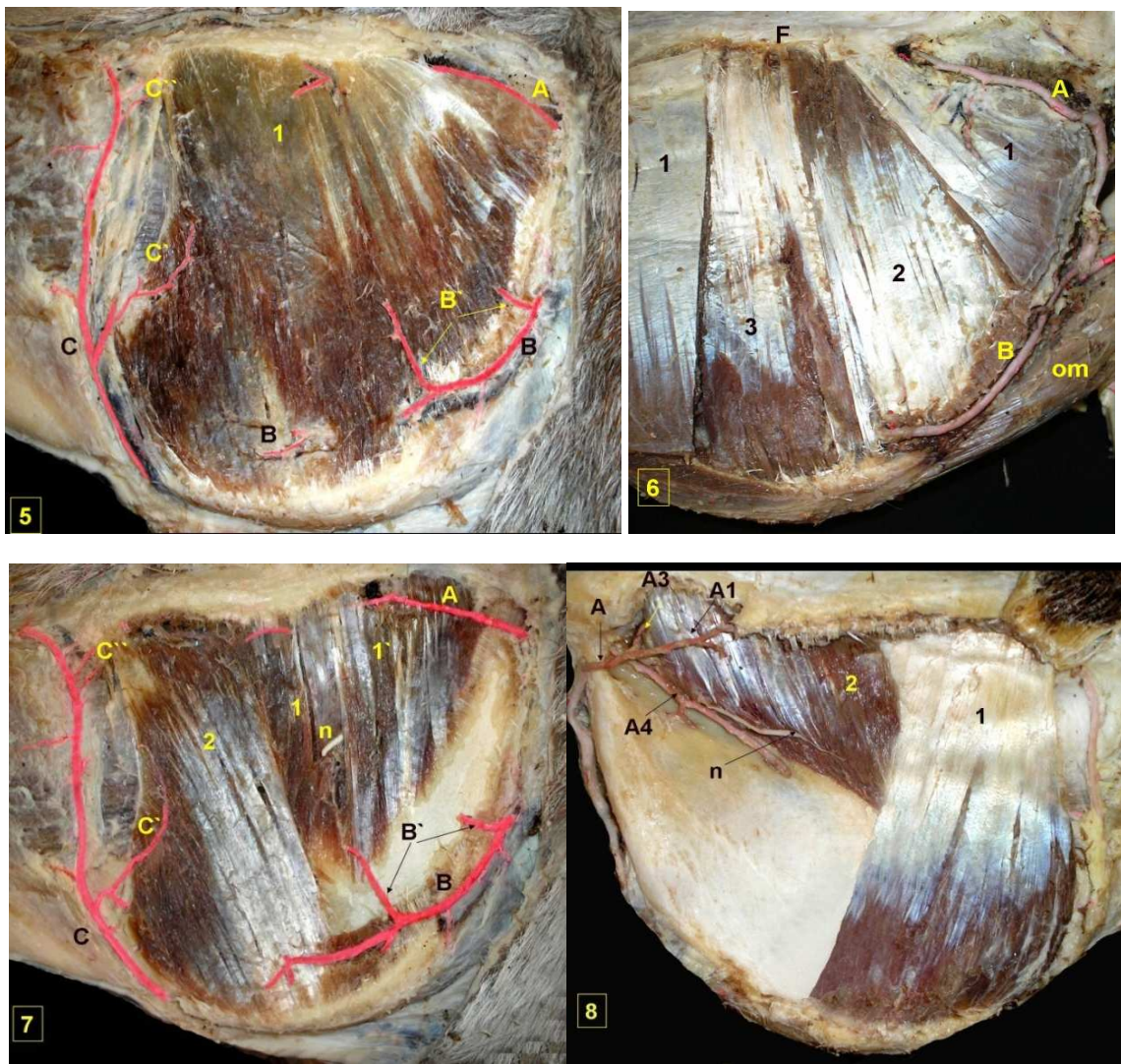

Fig. (5) Photograph showing the intermediate layer of the masseter muscle. (Left side).

A Transverse facial artery (superficial branch), B Masseteric arter, B' Muscular branches of B, C Facial artery, C' Ventral muscular branch of C, C" Dorsal muscular branches of C, 1 Intermediate layer of the masseter muscle.

Fig. (6) Photograph showing the $1^{\text {st }}, 2^{\text {nd }}$ superficial and intermediate masseteric layers (left side).

A Transverse facial artery, B Masseteric artery, F Facial crest, O Occipitomandibular muscle, 1 First superficial layer of the masseter muscle, 2 Second superficial layer of the masseter muscle, 3 intermediate layer of the masseter muscle.

Fig. (7) Photograph of showing the deep layer of the masseter muscle and $1^{\text {st }}$ layer of the maxillomandibular muscle. (Left side).

A Transverse facial artery (superficial branch), B Masseteric artery, B' Muscular branches of B, C Facial artery, $C^{\prime}$ Ventral muscular branch of C, C" Dorsal muscular branches of C, N Masseteric nerve, 1 Rostral part of the deep masseter muscle, 1' caudal part of the deep masseter muscle, 2 First layer of the maxillo-mandibular muscle.

Fig. (8) Photograph showing the $2^{\text {nd }}$ layer of the maxillo-mandibular muscle and zygomatico-mandibular (right side).

A Transverse fascial artery, A1 Superficial branch of A, A2 Deep branch (dorsal) of A, A3 Deep branch (ventral) of A, nMasseteric nerve, 1 Second layer of the maxilla-mandibular muscle, 2 Zygomaticomandibuar muscle.

J. vet. anat.

Vol 1 No1, (2008) $38-47$ 


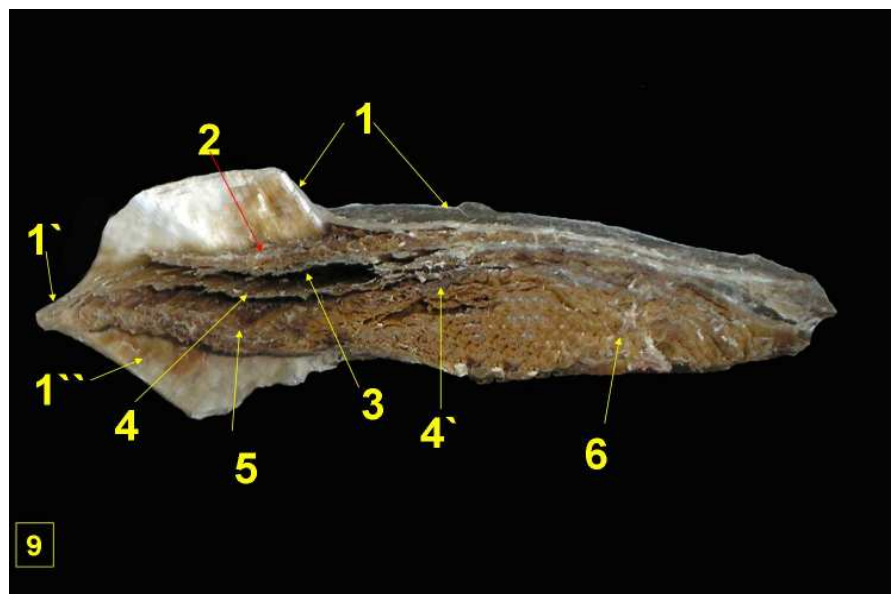

Fig. (9) Photograph showing the laminar arrangement of the masseter muscle. (frontal section

1 First superficial layer of the masseter muscle,1' Compact tendon, 1" Turned tendon, 2 Second superficial, layer of the masseter muscle, 3 Intermediate masseteric layer, 4 Rostral part of the deep masseteric layer, 4' Caudal part of the deep masseteric layer, 5- First layer of maxillo-mandibular muscle, 6 Zygomatico-mandibular muscle.
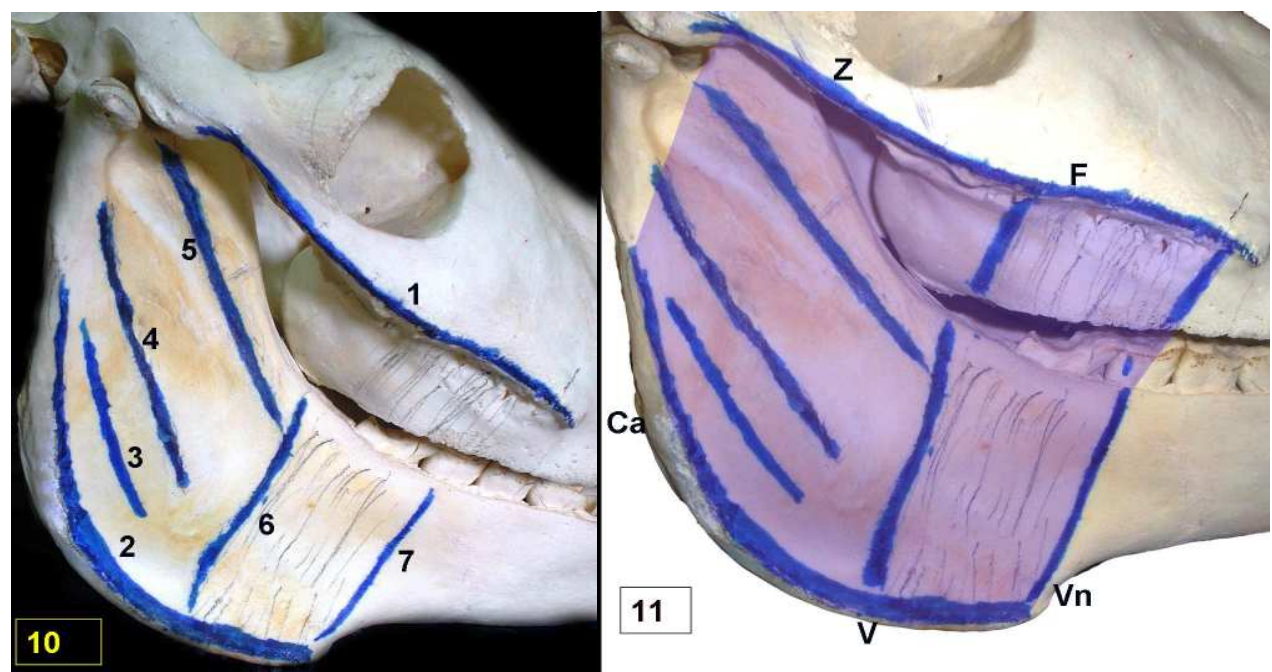

Fig. (10) Donkey skull showing the lines of the attachment of the different masseter muscle layers.

(right side).

1 Facial crest and zygomatic arch, 2 Ventral and caudal border of the ramus of the mandible, 3 Line of insertion of the intermediate masseteric layer, 4 Line of insertion of the deep masseteric layer, 5 Line of insertion of zygomatico-mandibular muscle, 6, 7 lines of attachment of maxillo-mandibular muscle.

Fig. (11) Donkey skull showing the attachment of the proper masseter muscle. (Colored purple).

$\mathrm{Ca}$ Caudal border of the Ramus of the mandible, F Facial crest, V- Ventral border of the Ramus of the mandible, Vn Vascular notch, Z Zygomatic arch.

J. vet. anat. 

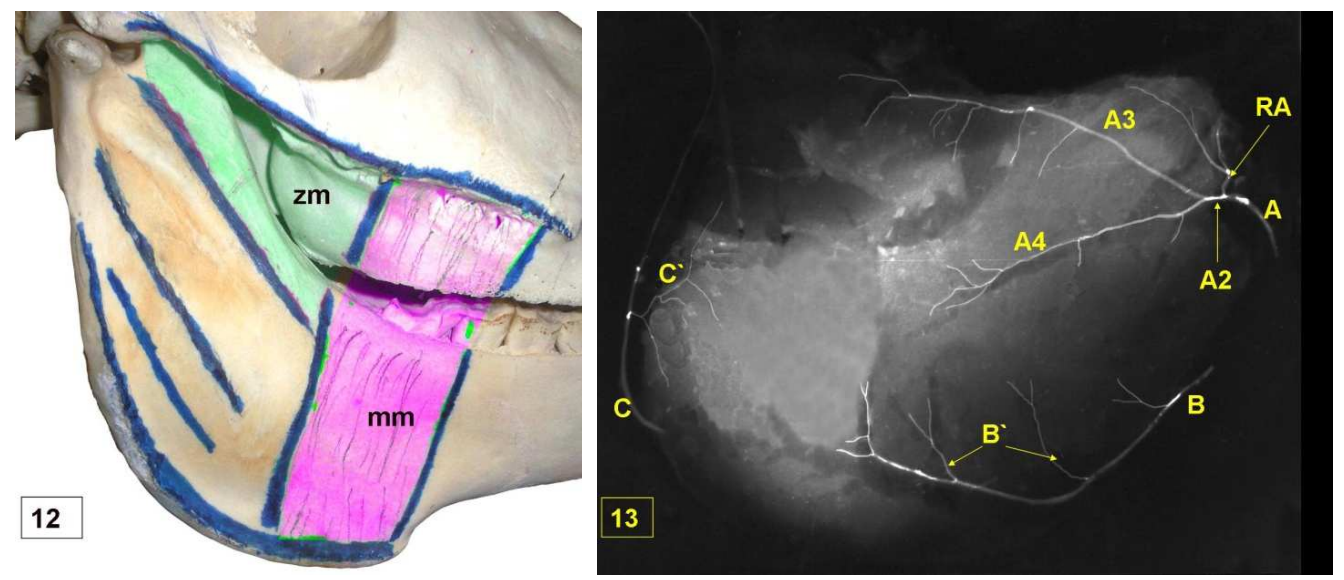

Fig. (12) Donkey skull showing the attachment of the improper masseter muscle.

$\mathrm{mm}$ maxillo-mandibular part (colored pink), zm zygomatico-mandibular part (colored green).

Fig. (13) Radiograph showing the arteries of the masseter muscle. (left side).

A A. transversa faciei, A1 R. profundus of $A$., A2 R. dorsalis of $A 1, A 3 R$. ventralis of $A 1, R A$. articularis of A, B A. Massetericus, B' Rr. musculares of $B, C$ A. Facialis, $C^{\prime}$ R. muscularis ventralis of $C$,

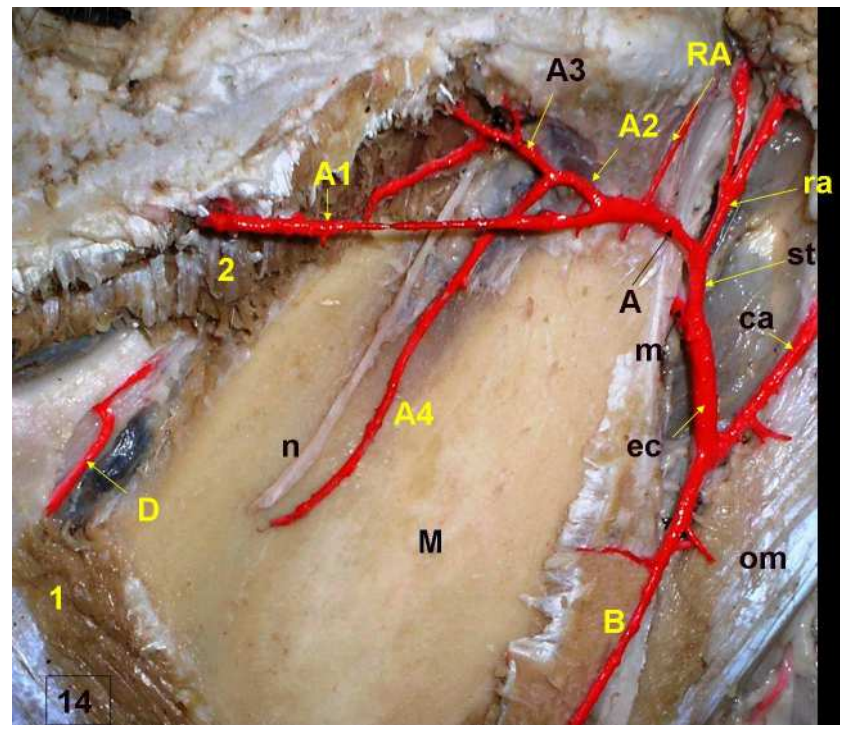

Fig. (14) Photograph showing the distribution of the transverse facial artery (left side). ec A. carotis externa, B A. massetericus, ca A. auricularis caudalis, St A. temporalis superficialis, ra A. auricularis rostralis, $A$ A. transversa faciei, $A 1 R$. superficialis of $A, A 2 R$. profundus of $A, A 3 R$. dorsalis of $A 2, A 4 R$. ventralis of $A 2, R A R$. articularis of $A, m$ A. maxillaris, D A. buccalis, M R. mandibulae (fossa massetericus), 1 M. maxillo-mandibularis (cut), 2 M. zygomatico-mandibularis (cut). 